Evaluating the Macroeconomic Effects of a Temporary Investment Tax Credit 


\section{Evaluating the Macroeconomic Effects of a Temporary Investment Tax Credit}

by Paul Gomme

\begin{abstract}
As part of a fiscal stimulus package, some members of Congress have recently proposed a temporary investment subsidy. This paper uses the neoclassical growth model to evaluate the likely macroeconomic effects of such a subsidy. The model predicts a 0.8 percentage point increase in output growth in the quarter that the policy is implemented. In subsequent quarters, the output growth effects are negligible. As the subsidy ends, output growth falls 1 percentage point before returning to its trend growth rate. While a permanent subsidy will lead to more capital deepening in the long term, it also represents a permanent fall in government revenues. Under a temporary subsidy, there is less capital deepening, but the decline in government revenues is likewise more modest.
\end{abstract}

Paul Gomme is an economic advisor at the Federal Reserve Bank of Cleveland. He thanks Ed Nosal and Mark Sniderman for helpful comments.
Materials may be reprinted if the source is credited. Please send copies of reprinted materials to the editor.

We invite questions, comments, and suggestions. E-mail us at editor@clev.frb.org. tions@clev.frb.org or fax it to 216-579-3050.

Policy Discussion Papers are available electronically through the Cleveland Fed's site on the World Wide Web: www.clev.frb.org/Research. 


\section{Introduction}

As part of a fiscal stimulus package, some members of Congress have recently proposed a temporary investment subsidy. A candidate proposal is to allow companies to immediately expense 30 percent of investment purchases made in the three-year period starting September 11, 2001; the remaining 70 percent is subject to the standard expensing provisions. This proposal may be motivated by the fact that capital deepening has been an important source of economic growth, particularly during the last expansion. This paper evaluates the likely consequences of implementing such a policy within a neoclassical growth model.

The proposed investment subsidy is temporary, but the available empirical evidence tells us only about the effects of permanent investment subsidies. Because of the lack of empirical data on the effects of temporary subsidies, we use a model to evaluate the effects of both permanent and temporary subsidies. Lucas (1976) shows that we should expect a temporary subsidy to have much different quantitative implications than a permanent one. In particular, when the subsidy is temporary, firms will have an incentive to change the timing of some of their capital spending in order to qualify for it.

Obviously, government policies change over time. We want to consider an environment in which firms rationally entertain the possibility of changes in government policy. In such an environment, there is a sense in which it would be irrational for firms to believe that any government policy is truly permanent. However, we can consider policies that are very long lived. So even for a permanent subsidy, our model allows a 1 percent probability that the subsidy will end. In particular, when a permanent subsidy is in place, there is a 99 percent probability that it will also be in place in the next quarter. Likewise, if no subsidy is currently in force, this situation will also persist into the next quarter with a probability of 99 percent. Naturally, firms' decisions take these probabilities into account. It is straightforward to show that, on average, periods of no subsidy will last 100 quarters (25 years); subsidy periods, likewise, last an average of 25 years. Of course, the probabilistic nature of changes in government policy imply that these periods may be longer or shorter than 25 years.

Next, we consider a temporary tax subsidy as currently proposed, and treat it as follows: We assume that there is a 1 percent likelihood that a three-year (12-quarter) investment subsidy will be put in place in the current quarter if no subsidy was in place during the previous quarter. At the end of that time, the investment subsidy ends; there is no uncertainty about either the length of the subsidy period, or the fact that the subsidy will end on the date announced. In future periods (after the end of the subsidy), there is a 1 percent chance of a temporary subsidy, again lasting 12 quarters. As with permanent subsidies, firms' decisions incorporate the likelihood of these changes in policy. Notice that while temporary subsidy periods last exactly 12 quarters, periods of no subsidy will last on average 100 quarters.

\section{Investment Behavior}

For the purposes of analyzing the effects of a subsidy to investment, the key relationship is the one governing firms' investment decisions. ${ }^{1}$ Firms face a cost of financing capital expenditures; we express that cost as an interest rate and call it the required rate of return. ${ }^{2}$ We can think of this required rate of return as the interest rate that firms would have to pay on a bank loan or corporate bonds. Each firm has a large number of potential investment projects that it could finance. The firm will implement those projects that have a rate of return at least equal to the required rate of return.
1. A detailed description of the model is presented in the technical appendix.

2. In the model, this required rate of return is determined by shareholders' preferences for goods today versus goods in the future. By investing more today, the firm reduces its current dividends, and so its shareholders' current consumption. This investment pays off in the form of higher future dividends, and so higher future consumption. 
The investment subsidy affects the effective price paid by firms for investment goods, and so the rate of return earned on investments. Consider a project that previously yielded a rate of return just equal to the required rate of return. Since this project still yields the same output and profits as before, the rate of return on the project must rise since its price has fallen. Intuitively, this situation is similar to what happens when the price of a bond falls while the coupon payments are unchanged; the effective yield of the bond rises. Since the return on all potential investment projects rises with the implementation of an investment subsidy, firms will increase the number of investment projects that they fund. This basic intuition, implying that firms will increase their capital spending, holds within the model despite the fact that there are general equilibrium effects at work that serve to increase the required rate of return. Specifically, there are strong consumption-smoothing forces in the model that imply the level of the capital stock adjusts gradually over time rather than all at once.

This paper uses a variant of the neoclassical growth model to analyze the effects of the investment subsidy. An important property of the model is that it has a unique steady state. ${ }^{3}$ That is to say, if we thought about running an arbitrarily long simulation of the model during which all sources of randomness are suppressed (in the current context, the investment subsidy remains at, say, zero), then eventually all variables will remain constant. A positive subsidy will result in a new steady state. While we could compare these steady states, we are more interested in the time paths of things like capital, investment, and output. If we only compared steady states, it would be difficult to make sensible statements about the effects of a temporary subsidy since, by its very nature, the temporary investment subsidy does not affect steady-state variables. Furthermore, by looking at time paths, we can consider the extent to which investment subsidies shift the timing of firms' investment.

\section{A Permanent Investment Subsidy}

To understand the longer-term effects of investment subsidies, we start by considering a permanent investment subsidy of 1.5 percent. Because there is a 99 percent likelihood that the subsidy persists into the next quarter, the expected value of the subsidy next quarter is slightly less than in the current quarter. In fact, it is 99 percent of the current subsidy rate. Consequently, firms act as if the subsidy will be in place into the indefinite future.

Recall that the subsidy raises the effective return on all investment projects. As a result, we expect the level of investment to rise permanently. Since an increase in investment leads to a higher capital stock, we expect the capital stock to rise as well. These predictions are borne out as can be seen in figure 1. In the long run, the capital stock rises almost 5.1 percent above its previous level (that is, without the investment subsidy). However, it takes a long time for the capital stock to fully adjust to its new level. Roughly half of the adjustment is achieved within seven years of the implementation of the subsidy. Investment responds a bit differently. It immediately rises 7.5 percent above its previous level, but in the longer run, the level of investment rises only 5.1 percent, the same percentage increase as the capital stock. This is not a coincidence. The increase in the capital stock implies that there will be more depreciation. Consequently, (gross) investment must rise in the long run to replace the depreciating capital. As the model economy settles into a new steady state, net investment (that is, net additions to the capital stock) falls to zero.
3. Strictly speaking, a second steady state exists in which there is no economic activity. 
We can, alternatively, express the effects of the permanent subsidy in terms of its effects on the growth rates of investment and output. As shown in figure 2(a), the growth rate of investment spikes up 7.5 percent in the quarter that the subsidy is put in place. Thereafter, the growth rate of investment is actually slightly negative, reflecting the gradual decline in investment shown in figure 1(b). The effect on the growth rate of output is similar to that on investment. On impact, the growth rate of output rises almost 0.65 percent; in subsequent quarters, the subsidy has a small but positive effect on output growth as shown in figure 2(b).

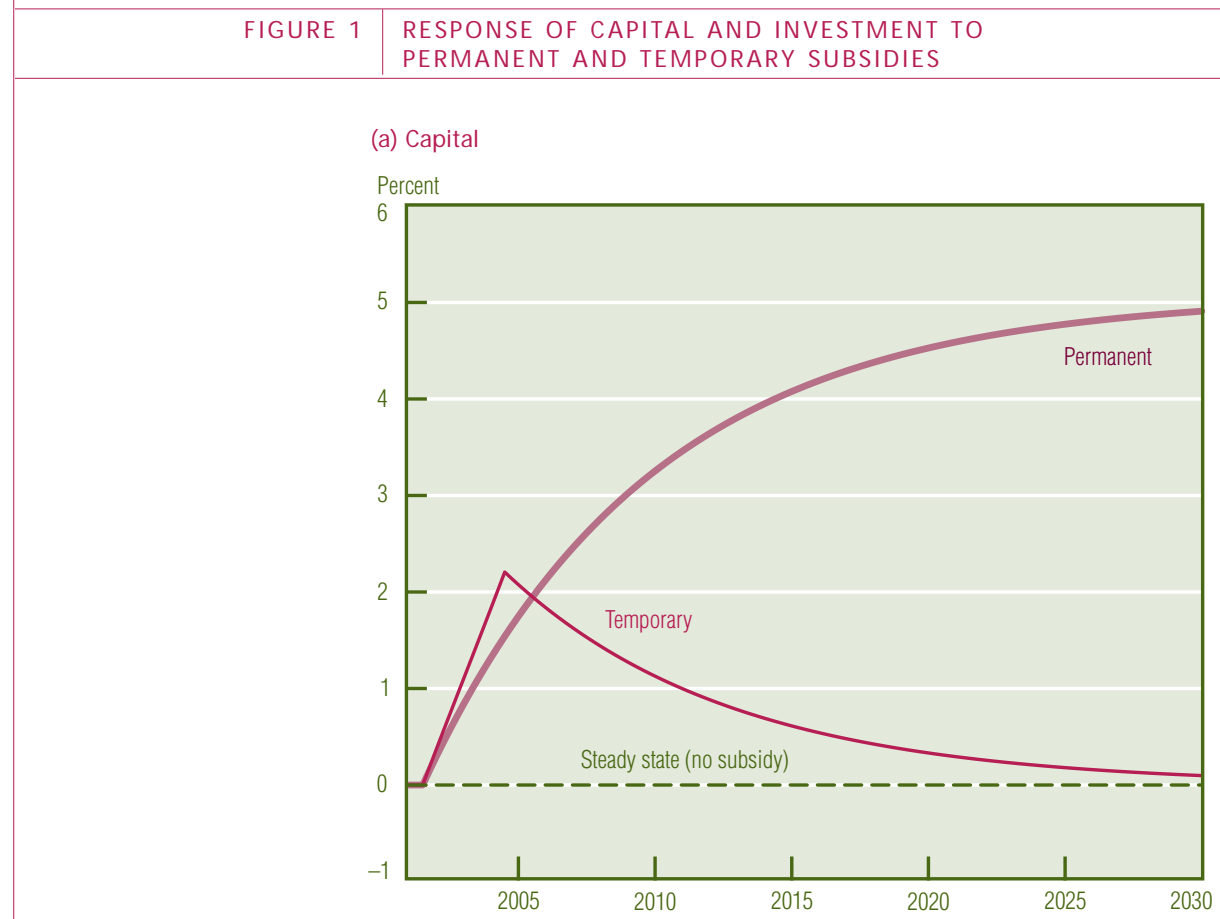

(b) Investment

Percent

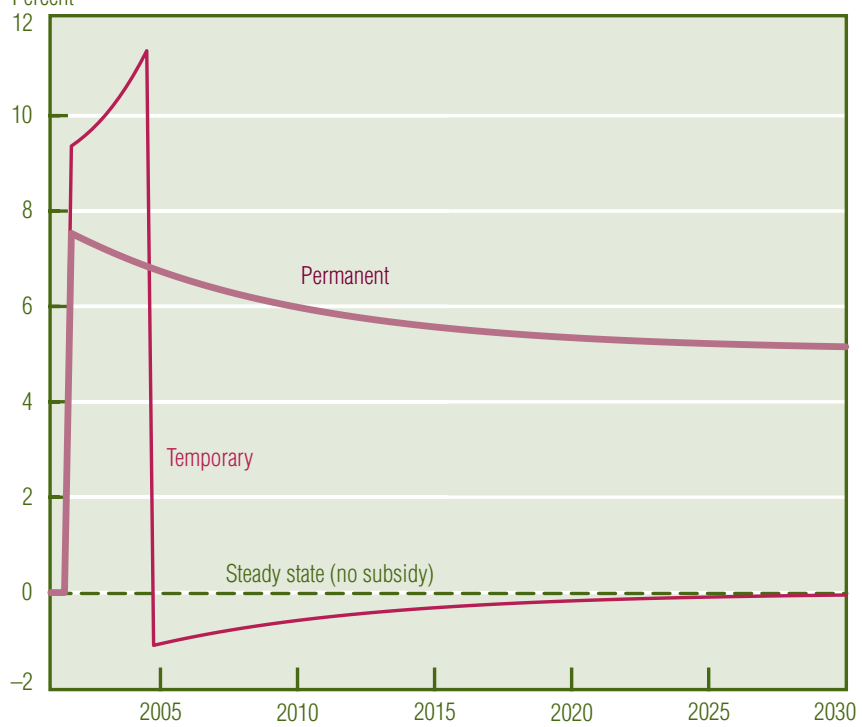




\section{A Temporary Subsidy}

As described above, under this scenario firms know that the investment subsidy will be in place for exactly 12 quarters, or three years. Returning to figure 1, we can see the effect of such a subsidy. The capital stock rises while the investment subsidy is in place, then gradually falls back to its previous level. Compared to the permanent subsidy case, the capital stock rises faster while the subsidy is in place. At its peak in 2004:IIIQ, capital is 2.2 percent above its previous level when the subsidy is temporary, compared with 1.5 percent when it is permanent. As shown in figure 1(b), the level of investment is also correspondingly higher under a temporary subsidy. Again, the peak is in 2004:IIIQ. When the subsidy is temporary, investment rises 11.4 percent above its presubsidy level; in the same quarter, investment is 6.8 percent above trend under a permanent subsidy. Thus, the temporary subsidy increases the amount of investment 4.6 percent more than the permanent subsidy.

(a) Investment
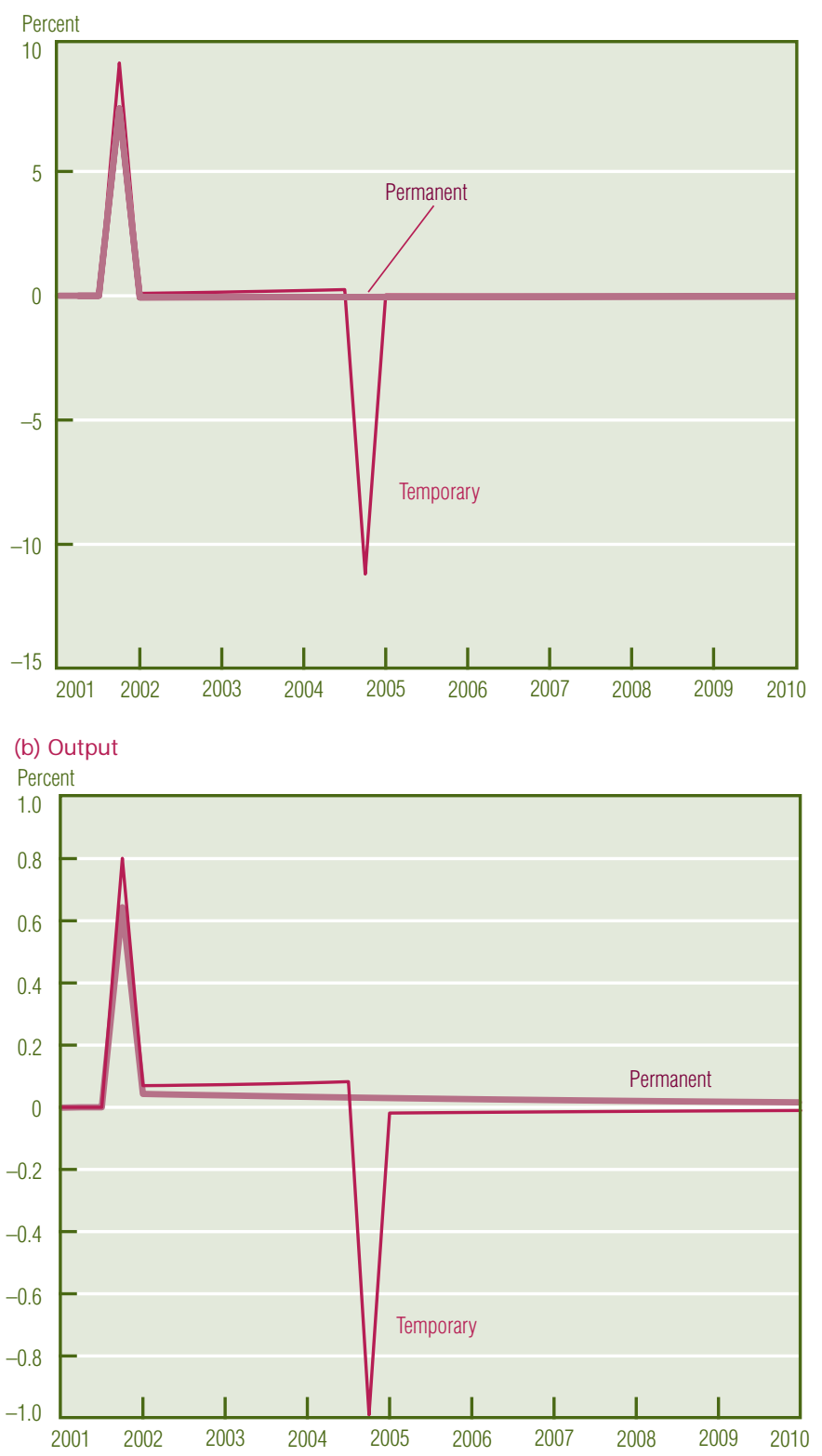
Once the subsidy ends, the price of capital rises, and firms lower their investment levels. The last quarter the subsidy is in place is 2004:IIIQ, so firms reduce their investment starting in 2004:IVQ.

In the model, firms react in a predictable way to the temporary nature of the investment subsidy. Specifically, they change the timing of some of their capital spending, moving it from quarters beyond 2004:IIIQ to quarters for which the investment subsidy is in place. Thus, we observe that the increase in the level of investment is as temporary as the investment subsidy. Figure 1(b) shows that the level of investment falls sharply after the investment subsidy expires in 2004:IVQ. In fact, investment is about 1 percent below its previous level for two years after the end of the subsidy as firms adjust their capital stocks back to their previous (presubsidy) levels.

In terms of growth rates, the growth of investment rises over 9.3 percentage points on impact, compared with 7.5 percentage points under a permanent subsidy. Throughout the subsidy period, investment remains slightly above its previous level with a temporary subsidy_about 0.1 percent in 2001:IVQ, rising to 0.25 percent in 2004:IIQ. However, in 2004:IVQ, the growth in investment plunges to -11.2 percent. Thereafter, investment growth is slightly positive. The effects on output growth are fairly similar. In particular, on impact the investment subsidy raises output growth by 0.8 percentage point (compared with 0.65 percentage point when the subsidy is permanent). Through the remainder of the subsidy period, output growth is enhanced by less than 0.1 percentage point. In 2004:IVQ, output growth falls 1 percentage point. In subsequent quarters, output growth is almost unchanged.

\section{Summary}

The neoclassical growth model described in this paper predicts that a temporary investment tax subsidy as described above will add roughly 0.8 percentage point to real output growth in the quarter that the subsidy is implemented. In the model, firms know at the beginning of 2001:IVQ that the subsidy will be in place in 2001:IVQ. Given the uncertainty over whether the subsidy will actually pass into legislation, we would expect that firms are not yet incorporating the subsidy into their capital acquisition plans. Consequently, these growth effects may be delayed. In terms of growth effects, it is probably good that the proposed legislation applies to investments made since September 11, 2001. Were this not the case, we would expect to see firms postponing their investment decisions, further lowering growth in the current quarter, until they see whether the legislation is enacted.

Under a temporary investment subsidy, the cost of boosting output and investment growth in 2001:IVQ is a subsequent fall in growth rates in 2004:IVQ as the subsidy ends. Specifically, the model predicts that output growth will fall 1 percentage point in 2004:IVQ. However, just as the growthenhancing effect of the subsidy is felt primarily in the quarter that the subsidy is put in place, the growthreducing effect of the end of the subsidy is also a one-quarter phenomenon. The fall in investment and output in 2004:IVQ could, of course, be avoided by making the subsidy permanent. Alternatively, the effects could be smoothed out over time through a more gradual phaseout of the subsidy.

From a policymaker's perspective, there are both costs and benefits of an investment subsidy. The chief benefit is increased economic activity owing to capital deepening. An important cost is the shortfall in government revenues. While a permanent subsidy will lead to more capital deepening in the long term, it also represents a permanent fall in government revenues. Under a temporary subsidy, there is less capital deepening, but the decline in government revenues is likewise more modest. 
There are a number of caveats to the analysis presented in this paper. First, the proposed legislation applies only to equipment and software with a life of 20 years or less. In the model, we assume that all capital expenditures (that is, those with lifespans longer than 20 years) received the subsidy. Consequently, the model likely overstates the growth rate effects. Since equipment and software investment is roughly two-thirds of total nonresidential investment, the impact of the subsidy may be closer to a 0.5 percentage point increase in output growth. Given the differential treatment of short-lived versus long-lived capital, the subsidy can be expected to distort the mix of capital in favor of shortlived capital. Since the model does not distinguish between these two types of capital, it is largely silent on this distortionary effect.

Second, in the model, we assume the temporary subsidy definitely ends after three years. It is not inconceivable that legislators may later decide to extend the subsidy. This possibility is absent from the model. If firms believe legislators are likely to extend the subsidy, then the analysis for the permanent subsidy case is the more relevant.

Third, a "capital overhang" is one of the stories that has been put forth as an explanation for why the U.S. economy entered a slowdown early in 2001. The essence of the overhang story is that firms overestimated the productivity-enhancing effects of the "New Economy" and acquired too much capital. Firms subsequently cut back on their investment expenditures in order to bring their actual capital stocks back into line with desired levels. Our analysis does not consider this possibility. If firms are still adjusting their capital stocks downward, then it is unlikely that an investment subsidy will have much effect on investment.

Fourth, the model is largely silent on the source of revenues used to finance the investment subsidy. In particular, the tax rates on labor and capital income are held fixed, and the subsidy is, in effect, paid for by a lump-sum tax. To the extent that the subsidy will be paid for through distortionary taxes (as opposed to nondistortionary lump-sum taxes) — either now or in the future- the subsidy may lead to negative economic consequences.

Finally, in the model firms are able to immediately increase their investment spending. Accounting for time-to-plan lags would delay the effects of the subsidy by the length of the planning period. For example, if it takes a quarter to plan capital projects, we would expect to see the growth rate effects starting in 2002:IQ. Incorporating time to build would tend to smooth the effects of the subsidy over the number of quarters it takes to build capital. If it takes four quarters to build new capital, then instead of a single quarter with output growth boosted 0.8 percentage point, we would expect to see four quarters during which output growth is roughly 0.2 percentage point higher. By the same token, time to build may cause investment to start falling before the end of the subsidy period, since some of the investment would take place in the postsubsidy period. 


\section{Technical Appendix: Neoclassical Growth Model}

\section{Households}

The representative household has preferences over time-dated streams of consumption, $c_{t}$, and leisure, $l_{t}$, given by:

$$
E_{0} \sum_{t=0}^{\infty} \beta^{t} U\left(c_{t} l_{t}\right)
$$

The household faces several constraints. First, the household must divide its time between leisure, $l_{t}$, and work, $h_{t}$ :

$$
l_{t}+h_{t}=1 \text {. }
$$

Second, it faces the following budget constraint:

$$
c_{t}+\left(1-\theta_{t}\right) x_{t}=\left(1-\tau_{H}\right) w_{t} h_{t}+\left(1-\tau_{K}\right) r_{t} k_{t}+\delta \tau_{K} k_{t}+T_{t} .
$$

The right-hand side of the above equation represents sources of income. Here, $w_{t}$ is the real wage while $r_{t}$ is the rental rate on capital. Labor earnings, $w_{t} h_{t}$, are taxed at the rate $\tau_{H}$ while capital earnings, $r_{t} k_{t}$, are taxed at the rate $\tau_{K}$. The term $\delta \tau_{K} k_{t}$ represents a capital consumption allowance. Finally, $T_{t}$ is a lump-sum transfer received from the government. The left-hand side gives uses of income. The household divides its income between consumption, $c_{t}$, and investment, $x_{t} . \theta_{t}$ is the rate at which investment purchases are subsidized.

The final constraint is the law of motion for capital, $k_{t}$ :

$$
k_{t+1}=(1-\delta) k_{t}+x_{t} .
$$

\section{Firms}

In this model, firms face a static problem: Taking factor prices as given, the typical firm hires capital and labor to maximize its profits,

$$
F\left(K_{t}, H_{t}\right)-r_{t} K_{t}-w_{t} H_{t} \text {. }
$$

It is assumed that the production function, $F$, is constant returns to scale. Since firms are also perfect competitors, in equilibrium firms earn zero profits. Consequently, we did not have to account for profit income when we specify the representative household's problem.

We could have accounted for firm ownership by introducing equity into the model and allowing firms to directly "own" capital. Provided firms act in the best interests of their shareholders (the representative household), the quantity allocations from the model will be the same. Firm ownership is suppressed in presenting the model since it merely complicates specifying the problems of the relevant economic actors. 


\section{Government}

The only role for government in this economy is to raise taxes, then redistribute the proceeds back to households in a lump-sum fashion. Since the government runs a balanced budget each period, its budget constraint is:

$$
T_{t}+\delta \tau_{K} K_{t}+\theta_{t} X_{t}=\tau_{H} w_{t} H_{t}+\tau_{K} r_{t} K_{t}
$$

\section{The Investment Subsidy}

To keep matters simple, assume that when investment is subsidized, the government does so at the rate $\bar{\theta}$. Consequently,

$$
\theta_{t} \in\{0, \bar{\theta}\}
$$

Notice that the absence of the investment subsidy is achieved by setting $\theta_{t}=0$.

\section{Temporary Subsidy}

If at date $t, \theta_{t}=0$, then with probability $\pi, \theta_{t+1}=0$. Alternatively, with probability $1-\pi$,

$$
\theta_{t}=\theta_{t+1}=\cdots=\theta_{t+11}=\bar{\theta}, \quad \theta_{t+12}=0
$$

That is to say, the tax subsidy is in place for exactly 12 quarters. Notice that while the subsidy lasts exactly 12 quarters, the length of time between subsidies is random. On average, periods of no subsidy last $1 /(1-\pi)$ quarters.

\section{Permanent Subsidy}

The permanent subsidy case is handled as a two-state Markov chain. We assume that the probability of remaining in a particular subsidy state is the same for the two subsidy rates. Thus,

$$
\operatorname{Pr}\left[\theta_{t+1}=0 \mid \theta_{t}=0\right]=\operatorname{Pr}\left[\theta_{t+1}=\bar{\theta} \mid \theta_{t}=\bar{\theta}\right]=\pi .
$$

Notice, then, that the probability of making a transition (no subsidy to positive subsidy or vice versa) is $1-\pi$. While the duration of a particular state is random, on average a state will last $1 /(1-\pi)$ quarters.

\section{Functional Forms and Calibration}

The period utility function is given by:

$$
U(c, l)= \begin{cases}\frac{\left(c^{\omega} l^{1-\omega}\right)^{1-\gamma}-1}{1-\gamma} & \text { if } 0<\gamma<1 \text { or } \gamma>1 \\ \omega \ln c+(1-\omega) \ln l & \text { if } \gamma=1 .\end{cases}
$$


The production function is parameterized as:

$$
F(K, H)=K^{\alpha} H^{1-\alpha}, \quad 0<\alpha<1 .
$$

Parameter values are summarized in table 1 . With the exception of the parameters governing the investment subsidy, these parameters are typical of those used in the real business cycle literature. The parameter $\omega$, which governs the labor-leisure trade-off, was chosen so that in steady state households work 33 percent of the time. This fraction matches up with evidence from time-use surveys.

TABLE 1 PARAMETER VALUES

Preferences

Risk aversion

1.0

Labor-leisure weight

$\gamma$

0.46

Discount factor

$\omega$

0.99

Technology

Capital share

$\begin{array}{ll}\alpha & 0.36\end{array}$

Depreciation

o $\quad 0.02$

Taxes

Labor

$\tau_{\mathrm{H}}$

0.25

Capital

$\tau_{\mathrm{K}}$

0.5

Investment Subsidy

Subsidy rate

$\bar{\theta}$

0.015

Persistence probability

$\pi$

0.99

\section{References}

Lucas, Robert E., Jr., "Econometric Policy Evaluation: A Critique," Carnegie-Rochester Conference

Series on Public Policy I, 1976, pp. 19-46. 


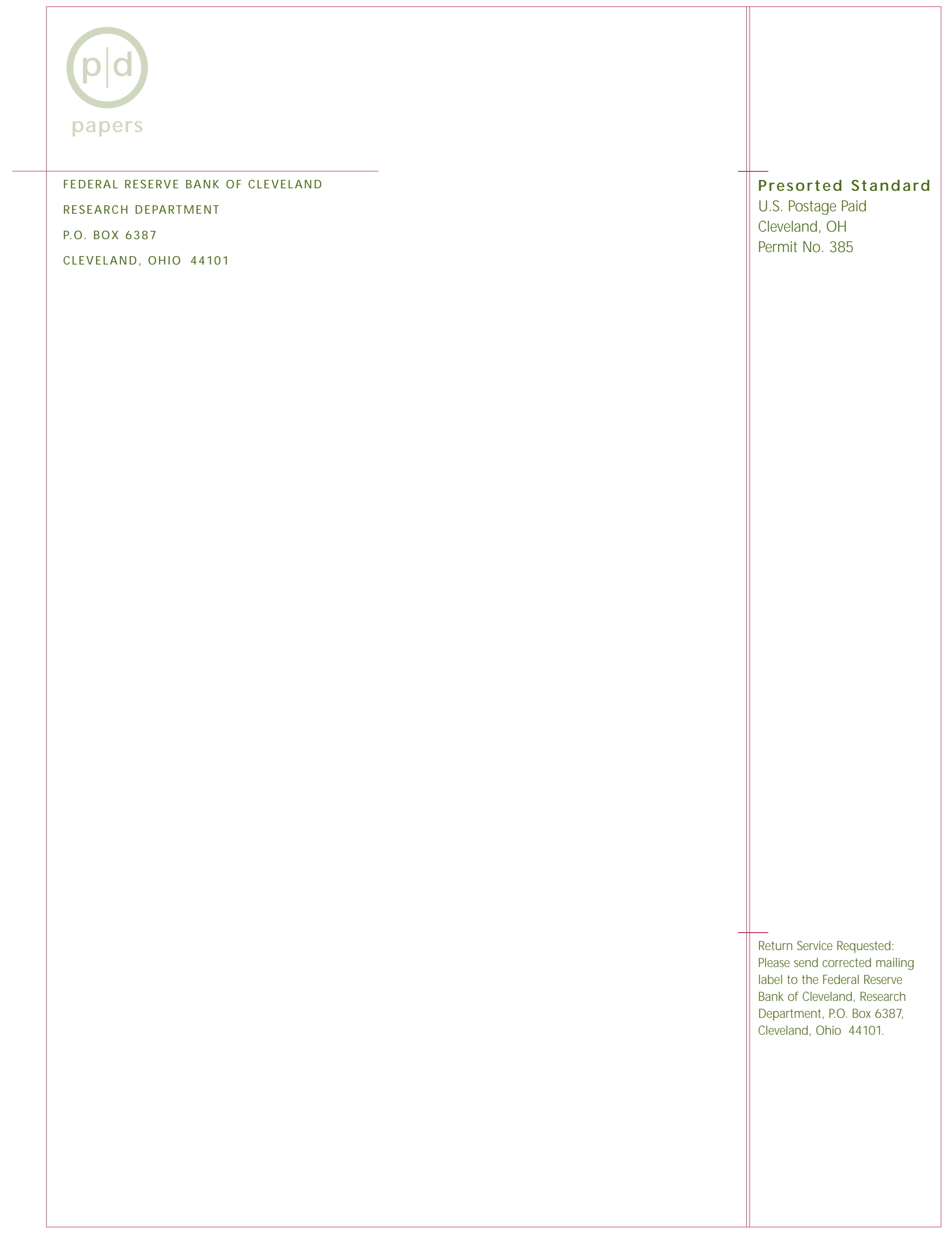

